\title{
Production and Characterization of Biodiesel from Aphanamixis polystachya Seed Oil
}

\author{
Sazia Ifteqar ${ }^{1}$, Rajia Sultana ${ }^{2}$,Sujit Banik ${ }^{3}$ and A. F. M. Mustafizur Rahman ${ }^{1, *}$ \\ ${ }^{I}$ Department of Applied Chemistry and Chemical Engineering, University of Dhaka, Dhaka-1000, Bangladesh \\ ${ }^{2}$ Centre for Advanced Research in Sciences (CARS), University of Dhaka, Dhaka-1000, Bangladesh \\ ${ }^{3}$ Institute of Fuel Research and Development, BCSIR, Dhaka-1205, Bangladesh
}

(Received : 4 December 2019; Accepted : 4 October 2020)

\begin{abstract}
The present study focuses on the utilization of non-edible Aphanamixis polystachya seed oil as a potential feedstock for the production of biodiesel. The extracted oil from non-edible seed could not be directly exploited for biodiesel production owing to its high free fatty acid (FFA) content of 5.785\%, so acid catalyzed esterification was applied to reduce FFA of oil to zero followed by base-catalyzed transesterification to convert esterified product to its mono-esters. Thermogravimetric analysis (TGA) revealed that the mass percentage corresponding to biodiesel under optimum conditions was $74.38 \%$. The conversion of the triglycerides in the oil into biodiesel through transesterification was confirmed using FT-IR spectroscopy. The elemental analysis of the produced biodiesel was studied. The produced biodiesel had properties which were comparable with biodiesel standards and could be utilized as an alternative diesel fuel without any hardware modifications.
\end{abstract}

Keywords: Aphanamixis polystachya seed oil, Biodiesel, Acid-catalyzed esterification, Base-catalyzed transesterification.

\section{Introduction}

The dwindling reserves of diesel have led researchers to find an alternative biodegradable, environmentally friendly diesel fuel 'Biodiesel'. Biodiesel is also known as the mono-alkyl ester of fatty acids can be derived by transesterification from oil seeds which grow abundantly in Bangladesh ${ }^{1}$. One such oil seed is the dark brown seeds of the plant, Aphanamixis polystachya (A. polystachya) belonging to the Meliacea family. This plant locally known as Pithraj, Roina, Tiktaraj is found extensively in the forests and hilly areas of south Asian countries. The seed oil is non-edible and therefore does not possess any threat to food supplies compared to the conventional edible seed oils used in biodiesel production ${ }^{2}$. The seeds also contain about $44 \%$ oil and plantation of this tree can reduce petroleum imports by $21 \%^{3}$. The seed oil has a high degree of unsaturation making it a suitable candidate for cold weather operations of diesel engines ${ }^{3}$.

The present study also involves the extraction of oil from $A$. polystachya seeds using $n$-hexane as solvent and the optimized two-step esterification process for the production of biodiesel with improved fuel properties. This study also shows the detail structural, thermal, elemental and physicochemical characterization of the produced biodiesel.

\section{Materials and Methods}

\section{Materials}

A. polystachya seeds were collected from Mithila Seed Company, Tongi, Gazipur, Bangladesh. The seeds having an initial moisture content of $25.484 \mathrm{wt} \%$ were washed, cleaned and sun dried until they attained a moisture content of 6.71 $\mathrm{wt} \%$. The seeds were ground to fine powder using a mortar to utilize them for oil extraction. All the chemicals utilized in this research work were of analytical reagent grade. $n$ Hexane (96\% pure) was purchased from Daejung Chemicals and Metals Company Limited, South Korea. Methanol (99.5\% pure) and sulfuric acid (98\% pure) were purchased from Merck KGaA, Germany. Potassium hydroxide pellets were purchased from Riedel-de Haen, United States.

\section{Extraction of Oil from Seed Powder}

A. polystachya seed oil content in seed was determined by soxhlet extraction using $n$-hexane as solvent ${ }^{4}$. About $50 \mathrm{gm}$ of dried seed powder was taken in a porous bag. The bag was placed inside a soxhlet apparatus that was suspended above a $500 \mathrm{~mL}$ round-bottom flask containing about 250 $\mathrm{mL}$ of $n$-hexane and below a reflux condenser. The flask was heated with a $500 \mathrm{~mL}$ heating mantle (Glassco Laboratory Instruments, India). The extraction process was optimized by carrying out the extraction of oil at five different extraction times $(30,60,90,120$ and $150 \mathrm{~min})$ in order to achieve the highest oil percentage. At the end of the extraction period, the flask containing $n$-hexane and the oil were removed and the residual solvent and moisture were separated by distilling the oil-solvent mixture at the boiling point of $n$-hexane $\left(68.7{ }^{\circ} \mathrm{C}\right)$. After completion of distillation, the $n$-hexane recovered was further utilized for the extraction of oil. Dark brown viscous oil was obtained whose oil content is determined by the following formula:

$$
\text { Oil }(\%)=\frac{\text { weight of oil obtained in gram }}{\text { weight of the seed powder in gram }} \times 100
$$

The oil was then analyzed for its different physico-chemical properties to evaluate its use towards biodiesel production.

\section{Production of Biodiesel}

Two step esterification processes were carried out from oil conversion to biodiesel. In the first step is acid-catalyzed esterification is used, while in the second step, alkalicatalyzed transesterification process is personalized. The acid-catalyzed esterification is a pretreatment step that reduces the FFA content of the crude oil below $2 \%$ using an acid catalyst. $100 \mathrm{~mL}$ of A. polystachya seed oil was poured into the flask and heated to about $40{ }^{\circ} \mathrm{C}$. The methanol was 
then charged into the flask and the mixture of methanol and preheated oil was stirred for a few minutes. Catalyst sulfuric acid was then added to the reaction mixture. Heating and stirring was continued until the reaction went to completion. The process was optimized by varying each experimental parameter while keeping other parameters constant. The following four parameters were varied:

1. Amount of methanol ( $30,40,50,60,70$ and 80 vol\% of oil)

2. Amount of sulfuric acid catalyst (1.0, 1.5, 2.0 and 2.5 vol\% of oil)

3. Reaction temperature $\left(40,50,60,70\right.$ and $\left.80{ }^{\circ} \mathrm{C}\right)$

4. Reaction time $(30,45,60,75,90$ and $100 \mathrm{~min})$

The reaction mixture was poured into a separating funnel and allowed to settle under gravity for $1 \mathrm{~h}$. The excess methanol, along with sulfuric acid and impurities moved to the upper phase and were removed. The lower layer which consisted of the esterified oil was separated and its acid value and FFA content was determined by standard titrimetric method. The optimum condition having the lowest FFA content was used for the main transesterification reaction.

In base-catalysed transesterification, $\mathrm{KOH}$ pellets were dissolved completely in required amount of methanol to prepare methanolic $\mathrm{KOH}$ solution. About $100 \mathrm{~g}$ of the pretreated oil was heated to $40{ }^{\circ} \mathrm{C}$ and then $\mathrm{KOH}$ methanolic solution was charged into the reaction flask and heating and stirring was continued at $400 \mathrm{rpm}$ at the required temperature for the required time until the transesterification was completed. To achieve a higher yield of biodiesel, the process was optimized by varying the following four parameters.

1. Amount of methanol $(20,30,40,50,60$ and $70 \mathrm{wt} \%$ of oil)

2. Amount of $\mathrm{KOH}(0.5,0.65,0.8,1.0,1.2$ and $1.4 \mathrm{wt} \%$ of oil)

3. Reaction temperature $\left(40,50,60,70\right.$ and $\left.80{ }^{\circ} \mathrm{C}\right)$

4. Reaction time $(30,60,90,120$ and $150 \mathrm{~min})$

After the completion of the reaction, the reaction mixture was poured into a separating funnel and allowed to settle for 16 hrs. After 16 hours, the reaction mixture separated into two layers. The upper layer consisted of methyl ester and the lower layer consisted of glycerol and impurities. The lower layer was drawn off. Each experiment was conducted three times in order to reduce the experimental errors.

\section{Biodiesel Purification}

After the separation of glycerol, water washing of biodiesel was performed to remove the impurities present in the product. The methyl ester was mixed with hot $\left(60{ }^{\circ} \mathrm{C}\right)$ distilled water (10 vol\% of ester) and allowed to settle under gravity in the separating funnel. Two layers were formed, the upper layer was of biodiesel, and the lower layer comprised of water and impurities. This process was repeated until the lower layer had a $\mathrm{pH}$ similar to the $\mathrm{pH}$ of distilled water, indicating that the biodiesel was free of catalyst. This was achieved after washings and then the product was allowed to settle under gravity overnight. The biodiesel collected from the upper layer was distilled to remove any traces of methanol in it and yield of biodiesel was calculated using the following equation ${ }^{5}$.

Yield $\left.(\%)=\frac{\text { Weight of produced biodiesel }}{\text { Weight of pretreated oil }} \times 100\right)$

\section{Characterization of Produced Biodiesel}

The elemental analysis of the biodiesel sample was performed using CHNS elemental analyzer (varioMicro V1.6.1, GmbH, Germany). The samples were weighed into a silver capsule and placed in the auto sampler carousel and analyzed for $800 \mathrm{~s}$. The combustion and reduction temperature were $1150{ }^{\circ} \mathrm{C}$ and $850{ }^{\circ} \mathrm{C}$, respectively. The flow rate of helium and oxygen were $200 \mathrm{~mL} / \mathrm{min}$ and 14 $\mathrm{mL} / \mathrm{min}$, respectively. One drop of the produced biodiesel and the extracted oil were separately placed in the sample holder. The FT-IR spectra was obtained by FT-IR Spectrophotometer (Model: IRPrestige-21, Shimadzu Corporation, JAPAN) equipped with an Attenuated Total Reflectance (ATR) device in the wave number range 700 $4000 \mathrm{~cm}^{-1}$ with 20 scanning rate with resolution of $4 \mathrm{~cm}^{-1}$. The FT-IR spectrum was taken in a transmittance mode. The thermogravimetric analysis (TGA) of biodiesel was conducted in a TGA-50H Thermogravimetric Analyzer, Shimadzu, Japan from room temperature $\left(25.67{ }^{\circ} \mathrm{C}\right)$ to $599.29{ }^{\circ} \mathrm{C}$ with a heating rate of $10{ }^{\circ} \mathrm{C} / \mathrm{min}$ under nitrogen atmosphere with a flow rate of $10 \mathrm{~mL} / \mathrm{min}$. The fuel properties of $A$. polystachya oil and the produced biodiesel were determined using standard test procedures.

\section{Results and Discussion}

\section{Effect of extraction time on oil content}

The extraction process was optimized by using six different extraction times $(30,60,90,120,150$ and $180 \mathrm{~min})$ while keeping the amount of seed powder and volume of $n$ hexane constant at $50 \mathrm{gm}$ and $250 \mathrm{~mL}$, respectively. The variation of the oil percentage with the extraction time is shown in Fig. 1. With increase in the extraction time, the solubility of the oil in the solvent was enhanced so the extraction rate increased and the amount of oil extracted increased. When the extraction time was increased from 150 to $180 \mathrm{~min}$, the oil content was almost constant. It was because nearly all the free oil on the surface of the seeds was solubilized in the fresh n-hexane over the course of 150 min. Therefore an extraction time of $150 \mathrm{~min}$ was used as the optimum time for extraction for which the oil content was found to be $39.33 \%$. This oil content of was comparable to that of jatropha $(55 \%)^{6}$, castor $(55 \%)^{7}$ and rubber seed oil $(45 \%)^{8}$ which are the conventional seed oils used for biodiesel production.

\section{Physico-chemical characterization of extracted seed oil}

The physico-chemical properties of the extracted seed oil were determined by the following standard test procedures and are listed in Table I. The free fatty acid (FFA) of the extracted oil was determined from its acid value. The FFA content of the extracted oil $(5.785 \%)$ did not lie within the 
acceptable limit (3-5\%) for base-catalyzed trans-esterification and may lead to soap formation making it difficult to separate the glycerol layer from biodiesel layer and result in lower yield of the methyl ester ${ }^{9}$. The kinematic viscosity of the oil at $40{ }^{\circ} \mathrm{C}$ was very high $(33.568 \mathrm{cSt})$ and would result in the formation of large droplets on direct injection which would cause poor combustion, increased exhaust smoke and emissions, wear of gear train, camshaft and tappets of the set of injection pumps due to the higher injection pressures, excessive pressure losses in the piping system and poor atomization. The high volatility of the oil due to its low flash point makes the oil unsuitable as a fuel for diesel engines. Therefore a dual step process was developed for the production of biodiesel from the extracted seed oil ${ }^{10}$.

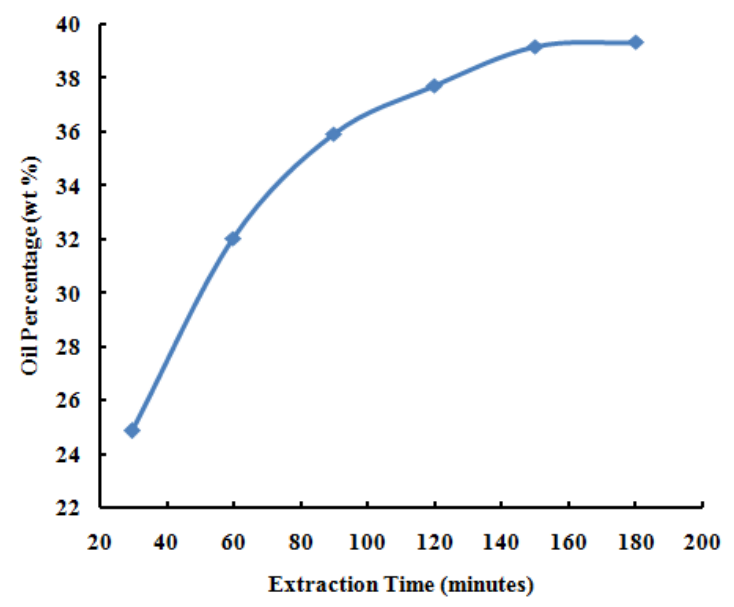

Fig. 1. Variation of oil content with extraction time.

\section{Acid-catalyzed esterification}

\section{Effect of amount of methanol}

Methanol was used to carry out the esterification of the extracted oil. The acid value and FFA content was determined for different amount of methanol ( 30, 40, 50, 60,70 and $80 \mathrm{vol} \%$ of oil) keeping the amount of $\mathrm{H}_{2} \mathrm{SO}_{4}$ catalyst constant at $0.5 \mathrm{vol} \%$, temperature constant at $60{ }^{\circ} \mathrm{C}$ and time constant at $90 \mathrm{~min}$.

Table 1. Physico-chemical characterization of extracted A. polystachya seed oil

\begin{tabular}{|c|c|c|}
\hline Parameters & Testing Procedure & $\begin{array}{c}\text { A. polystachya } \\
\text { oil } \\
\end{array}$ \\
\hline Colour Index & ASTM D 1500-64 & 0.5 \\
\hline Density at $15^{\circ} \mathrm{C}, \mathrm{g} / \mathrm{cm}^{3}$ & IP $160 / 57$ & 0.924 \\
\hline $\begin{array}{l}\text { Kinematic Viscosity at } \\
40^{\circ} \mathrm{C}, \mathrm{cSt}\end{array}$ & ASTM D 445-65 & 33.568 \\
\hline $\begin{array}{l}\text { Kinematic Viscosity at } \\
100^{\circ} \mathrm{C}, \mathrm{cSt}\end{array}$ & ASTM D 445-65 & 9.79 \\
\hline Flash Point, ${ }^{\circ} \mathrm{C}$ & ASTM D 93-62 & 30 \\
\hline Pour Point, ${ }^{\circ} \mathrm{C}$ & ASTM D 97-57 & -11 \\
\hline Acid value, mg KOH/gm & IP $1 / 58$ & 11.57 \\
\hline FFA, $\%$ & IP $1 / 58$ & 5.785 \\
\hline Water content, vol\% & IP 74/57 & 0.36 \\
\hline Ash content, wt $\%$ & ASTM D 482-63 & 1.23 \\
\hline Carbon residue, wt\% & ASTM D 189-65 & 1.17 \\
\hline Calorific value, $\mathrm{KCal} / \mathrm{kg}$ & IP $12 / 58$ & 8571.42 \\
\hline
\end{tabular}

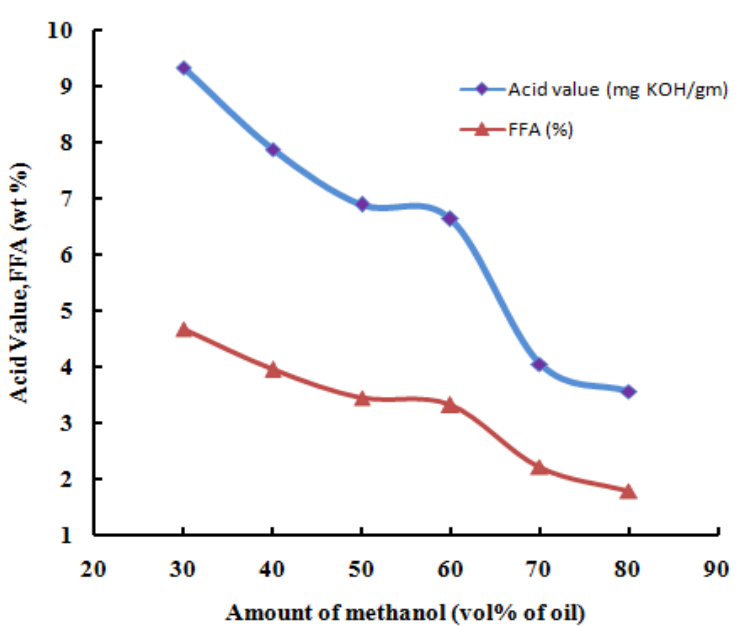

Fig. 2. Variation of acid value and FFA content with the volume of methanol.

The variation of the acid value and FFA content with the amount of methanol is shown in Fig. 2. With increase in the amount of methanol from 30 to $80 \mathrm{vol} \%$, the FFA content was seen to decrease significantly from 4.670 to $1.780 \%$ due to the increase in solubility of methanol in the extracted oil which resulted in higher reaction rate with the FFA present in the oil. This is in agreement with other researchers who used excess quantities of methanol while using sulfuric acid as a catalyst ${ }^{11}$. Therefore the optimum amount of methanol to be used for acid-catalyzed esterification was 80 vol\% of oil for which the FFA content was the lowest.

\section{Effect of amount of sulfuric acid catalyst}

Sulfuric acid was used as the catalyst for the acid pretreatment of the oil. The acid value and FFA content was determined for different amount of sulfuric acid catalyst $(1.0,1.5,2.0$ and 2.5 vol\% of oil) keeping the amount of methanol constant at $80 \mathrm{vol} \%$, temperature constant at 60 ${ }^{\circ} \mathrm{C}$ and time constant at $90 \mathrm{~min}$.

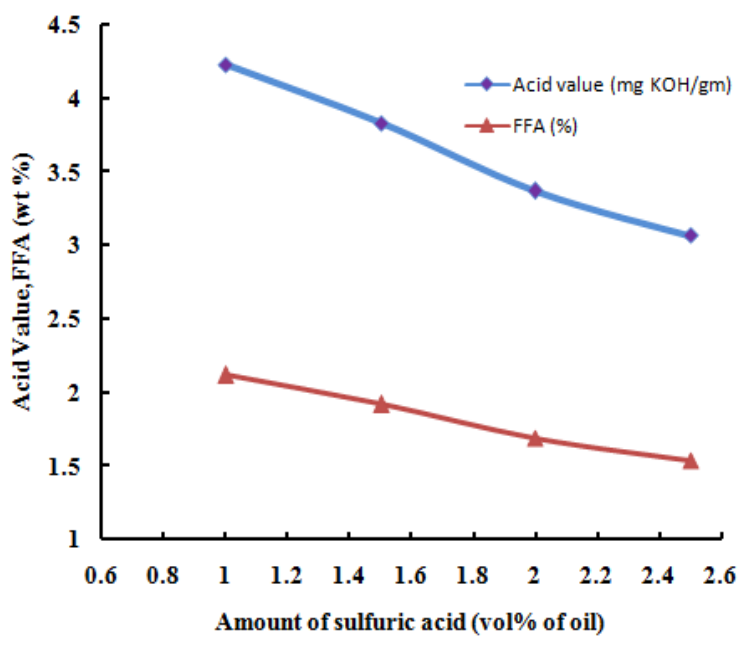

Fig. 3. Variation of acid value and FFA content with the amount of sulfuric acid. 
The variation of the acid value and FFA content with the amount of sulfuric acid is shown in the Fig. 3. The lowest FFA content of $1.533 \%$ was observed for 2.5 vol\% sulfuric acid. It should be noted that when the experiment was carried out using 3.0 vol\% sulfuric acid catalysts, a dark colored product was obtained and it was not possible to distinguish the methanol layer from the esterified layer, therefore excess amount of sulfuric acid should be avoided. A lower amount of sulfuric acid than 2.5 vol\% would cause a reduction in biodiesel conversion.

\section{Effect of reaction temperature}

The acid value and FFA content of the oil was determined for different reaction temperatures $(40,50,60,70$ and 80 $\left.{ }^{\circ} \mathrm{C}\right)$ keeping the amount of methanol constant at $80 \mathrm{vol} \%$, amount of sulfuric acid catalyst constant at $2.5 \mathrm{vol} \%$ and time constant at $90 \mathrm{~min}$. The results are shown in Fig. 4. With increase in temperature from 40 to $70{ }^{\circ} \mathrm{C}$, the FFA content decreased from 2.423 to $1.642 \%$ and then showed a rise in value of $1.710 \%$ on reaching $80{ }^{\circ} \mathrm{C}$. This was because at low temperature, conversion of FFA to methyl ester was very low even after stirring the mixture for a long time but as the temperature increased, the conversion also increased simultaneously due to increase in diffusion rate owing to increase in solubility of the solvent in the oil. But as the temperature crossed $70^{\circ} \mathrm{C}$, the acid value and FFA content showed a slight rise which may be due to the loss of methanol from the reaction mixture and the product also exhibited a dark color at this temperature. Another reason for the increase in FFA content beyond $70{ }^{\circ} \mathrm{C}$ is the burning of the oil by sulfuric acid. Moreover, high temperature would also cause an increase in the production cost of biodiesel in industry. Therefore, the optimum temperature for acid pretreatment process was $70{ }^{\circ} \mathrm{C}$.

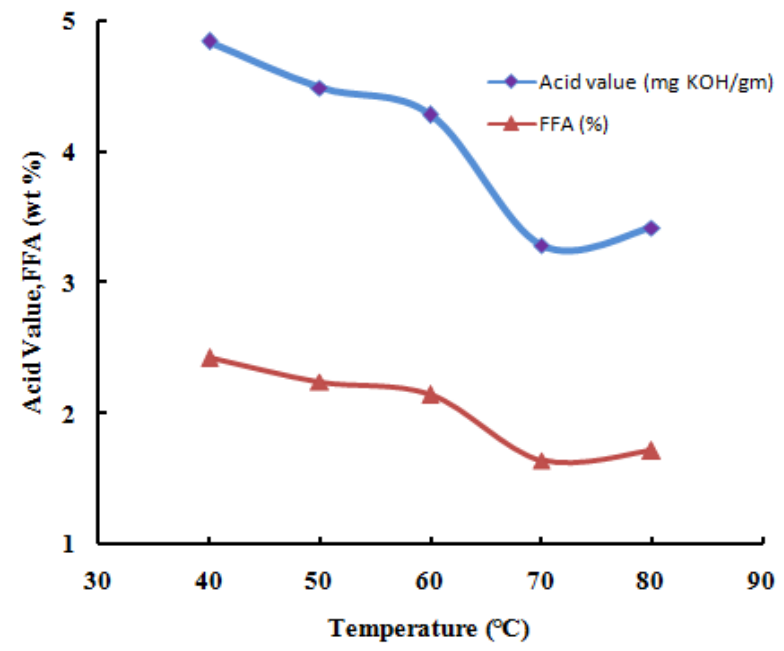

Fig. 4. Variation of acid value and FFA content with reaction temperature.

\section{Effect of reaction time}

The acid value and FFA content was determined for different reaction time $(30,45,60,75,90$ and $105 \mathrm{~min})$ keeping the amount of methanol constant at $80 \mathrm{vol} \%$, amount of sulfuric acid constant at $2.5 \mathrm{vol} \%$ and reaction temperature constant at $70{ }^{\circ} \mathrm{C}$. The results are shown in Fig. 5. With increase in reaction time from 30 to $60 \mathrm{~min}$, there was a decrease in FFA content from 3.747 to $0.935 \%$ and then again from 60 to $105 \mathrm{~min}$, there was increase in FFA content from 0.935 to $1.383 \%$. The FFA content may have decreased up to $60 \mathrm{~min}$ because a time of $60 \mathrm{~min}$ was required owing to proper contact between the reactant and the oil resulting in higher conversion of the FFA into esters but beyond $60 \mathrm{~min}$, the increase in FFA may be due to decomposition of methyl ester as a result of prolonged time of stirring. Therefore, a reaction time of 60 min was chosen as the optimum time for acid-esterification process.

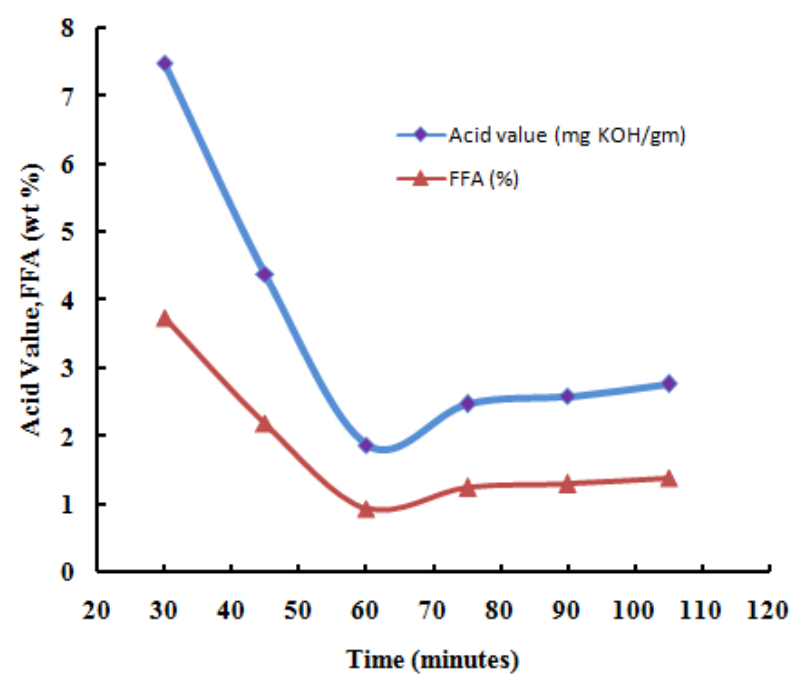

Fig. 5. Variation of acid value and FFA content with reaction time.

\section{Base-catalyzed transesterification}

\section{Effect of amount of methanol}

Methanol was used as the carrier of the catalyst, $\mathrm{KOH}$ in the transesterification of the pretreated oil. The yield of biodiesel was measured for different amount of methanol $(20,30,40,50,60$ and $70 \mathrm{wt} \%$ of oil) keeping the amount of $\mathrm{KOH}$ constant at $1.0 \mathrm{wt} \%$, reaction temperature constant at $60{ }^{\circ} \mathrm{C}$ and time constant at $90 \mathrm{~min}$. The result of the variation in the biodiesel yield with the amount of methanol is shown in Fig. 6. The biodiesel yield increased from 52.71 to $95.76 \mathrm{wt} \%$ with increase in the amount of methanol from 20 to $60 \mathrm{wt} \%$. This is because higher amount of methanol results in higher diffusion rate of the catalyst in the oil phase and therefore higher reaction rate with the FFA or triglycerides. But on addition of $70 \mathrm{wt} \%$ of methanol to the reaction mixture, there was a decrease in the yield of biodiesel to $67.80 \mathrm{wt} \%$ because the excess methanol favored the conversion of the triglycerides into monoglycerides as well as enhanced the contact between the methyl ester and glycerol molecules and favored the backward reaction forming monoglycerides ${ }^{12}$. Therefore 60 wt $\%$ of methanol was considered as the optimum amount of alcohol required for transesterification. 


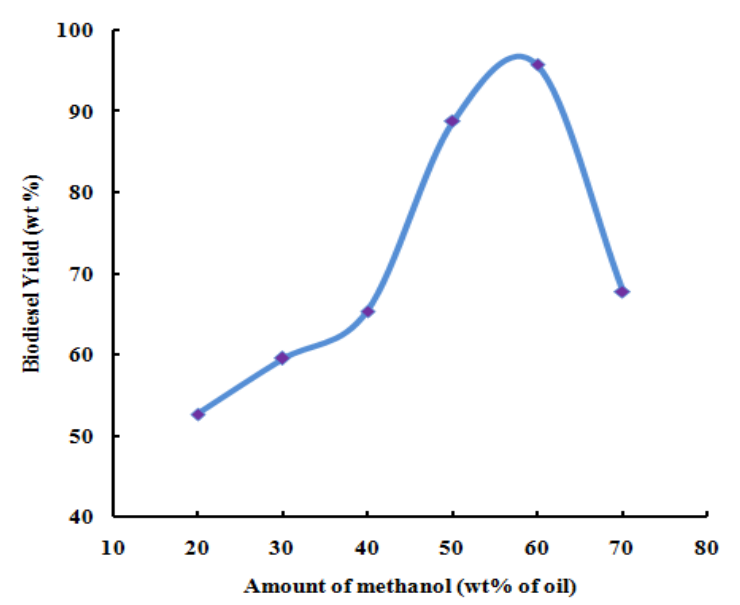

Fig. 6. Variation of Biodiesel yield with the amount of methanol.

\section{Effect of amount of $\mathrm{KOH}$}

$\mathrm{KOH}$ was used as the catalyst to carry out the transesterification reaction. The yield of biodiesel was measured for different amount of $\mathrm{KOH}(0.5,0.65,0.8,1.0$, 1.2 and $1.4 \mathrm{wt} \%$ of oil) keeping the amount of methanol constant at $60 \mathrm{wt} \%$, reaction temperature constant at $60{ }^{\circ} \mathrm{C}$ and time constant at $90 \mathrm{~min}$. The result of the variation in the biodiesel yield with the amount of $\mathrm{KOH}$ catalyst is shown in Fig. 7. As the $\mathrm{KOH}$ concentration was increased from 0.5 to $0.8 \mathrm{wt} \%$, the conversion of triglycerides as well as the ester content was increased from 52.15 to $95.06 \mathrm{wt} \%$. Insufficient amount of $\mathrm{KOH}$ resulted in incomplete conversion of the triglycerides as indicated by lower ester content and no transesterification reaction was observed below $0.5 \mathrm{wt} \%$ of $\mathrm{KOH}$. The ester content reached an optimum value at 0.8 wt $\%$ of $\mathrm{KOH}$ but beyond this concentration, the ester production decreased. This is because addition of excess alkaline catalyst caused the participation of more triglycerides in the saponification reaction and led to emulsion formation which resulted in increase in viscosity of the oil and gel formation. This gel hinders the separation of the glycerol from the biodiesel and thereby reduces the yield of biodiesel. These results were similar to biodiesel produced from Brassica carinata oil $^{13}$ and used frying oil.

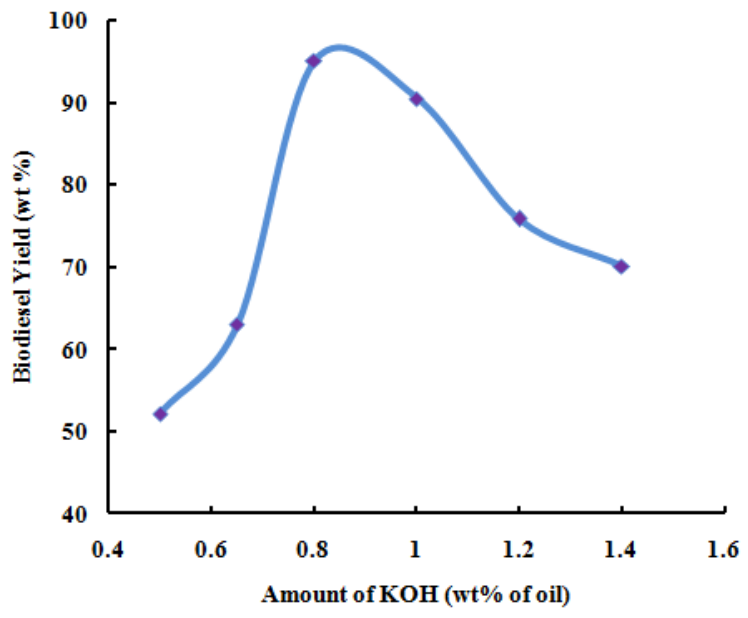

Fig. 7. Variation of Biodiesel yield with the amount of $\mathrm{KOH}$.

\section{Effect of reaction temperature}

The yield of biodiesel was measured for different reaction temperatures $\left(40,50,60,70\right.$ and $\left.80{ }^{\circ} \mathrm{C}\right)$ keeping the amount of methanol constant at $60 \mathrm{wt} \%$, amount of $\mathrm{KOH}$ constant at $0.8 \mathrm{wt} \%$ and time constant at $90 \mathrm{~min}$. The results of the variation in the biodiesel yield with the reaction temperature are shown in Fig. 8. With increase in temperature from 40 to $60{ }^{\circ} \mathrm{C}$, there was an increase in biodiesel yield from 56.05 to $94.91 \mathrm{wt} \%$. This was because with increase in temperature, the reaction rate increased and reduced the reaction time due to the reduction in viscosity of the oil. This increased the solubility of the oil in methanol and improved the contact between the oil and methanol molecules, thereby resulting in a better yield of methyl ester. Beyond $60{ }^{\circ} \mathrm{C}$ there was a decrease in biodiesel yield, the biodiesel yield was 79.47 and $66.58 \mathrm{wt} \%$ at 70 and $80{ }^{\circ} \mathrm{C}$, respectively. This decrease in yield at higher temperature may be due to the evaporation of methanol (boiling point: $64.7^{\circ} \mathrm{C}$ ). High temperature also accelerates the saponification of the glycerides by $\mathrm{KOH}$ before completion of alcoholysis. Therefore, $60{ }^{\circ} \mathrm{C}$ was considered as the optimum reaction temperature for transesterification. Similar trend was observed by researchers for neat and used frying oil and tobacco seed oil ${ }^{14}$.

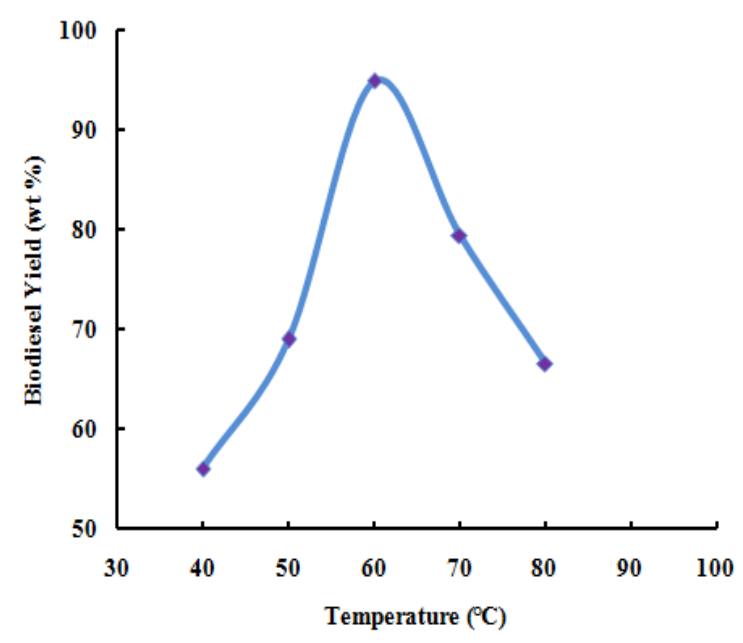

Fig. 8. Variation of Biodiesel Yield with reaction temperature.

\section{Effect of reaction time}

The yield of biodiesel was measured for different reaction time $(30,60,90,120$ and $150 \mathrm{~min})$ keeping the amount of methanol constant at $60 \mathrm{wt} \%$, amount of $\mathrm{KOH}$ constant at 0.8 wt $\%$ and reaction temperature constant at $60{ }^{\circ} \mathrm{C}$. The result of the variation in the biodiesel yield with reaction time is given in Fig. 9. With increase in reaction time from 30 to 120 minutes, the biodiesel yield showed a gradual increase from 68.03 to $96.67 \mathrm{wt} \%$. This was because with increase in time, perfect contact between the reagents was achieved with constant stirring. At $150 \mathrm{~min}$, the yield decreased to 74.47 wt $\%$ because prolonged time of stirring caused decomposition of the methyl esters into triglycerides. Therefore reaction time of $120 \mathrm{~min}$ was considered as the optimum time required for transesterification. 


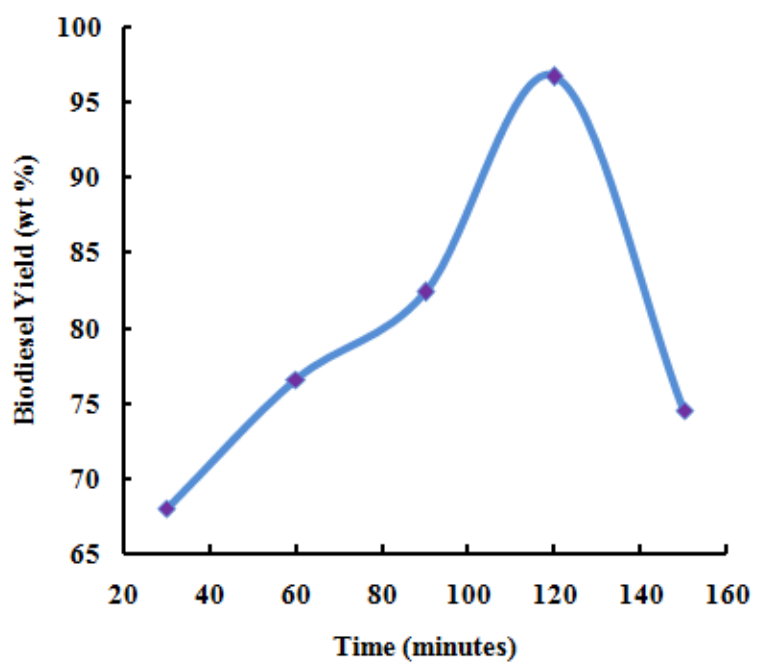

Fig. 9. Variation of Biodiesel Yield with reaction time.

\section{Elemental composition of produced biodiesel}

The elemental composition of the produced biodiesel from A. polystachya seed and biodiesel standard according to ASTM PS $121^{15}$ are given in Table II. The elemental composition reveals that the produced biodiesel contains significant amount of oxygen which would lead to complete and cleaner combustion and cause reduction in combustion delay and probability of fuel-rich zone formation which are prone to hydrocarbon and carbon monoxide emissions ${ }^{16}$. The high nitrogen content of the produced biodiesel indicates that there will be increased $\mathrm{NO}_{\mathrm{x}}$ emissions on burning this fuel. $\mathrm{NO}_{\mathrm{x}}$ is a major contributor of acid rain and human disease. It is also a primary pollutant in the formation of tropospheric ozone which is an important greenhouse gas. Some researchers have concluded that increased $\mathrm{NO}_{\mathrm{x}}$ emissions are also associated with higher oxygen content of biodiesel ${ }^{17,18}$. The composition of sulfur remains within the permissible limit and therefore the $\mathrm{SO}_{\mathrm{x}}$ emission hazards from this fuel will be low.

Table 2. Elemental analysis of produced biodiesel and biodiesel standard.

\begin{tabular}{lll}
\hline Sample & Produced Biodiesel & Standard Biodiesel \\
\hline Weight (mg) & 3.4030 & - \\
C $(\%)$ & 75.030 & 77 \\
H $(\%)$ & 12.619 & 12 \\
N $(\%)$ & 1.132 & 0.0 \\
S (\%) & 0.00 & $0.0-0.0024$ \\
O $(\%)$ & 11.219 & 11 \\
\hline
\end{tabular}

\section{Fourier Transorm- Infrared Spectroscopic Analysis}

The FT-IR spectra of the oil and biodiesel sample are given in Fig. 10 and are used to show that the triglyceride in the oil has been actually converted to biodiesel. On comparing the FT-IR spectra of A polystachya oil and its biodiesel, subtle differences are observed because the product of transesterification (fatty acid methyl Ester) is chemically similar to its precursor (oil). The main functional group of
A. polystachya seed oil are carboxylic acid $(\mathrm{C}=\mathrm{O})$ appears as main peak in $1741.72 \mathrm{~cm}^{-1}$ region and alkanes $(\mathrm{C}-\mathrm{H})$ that appears in 2856.58 and $2926.01 \mathrm{~cm}^{-1}$. The major peaks are in the region of $1735.93 \mathrm{~cm}^{-1}$ and $2927.94 \mathrm{~cm}^{-1}$. So the main functional groups of $A$. polystachya seed oil biodiesel are ester $(\mathrm{C}=\mathrm{O})$ appeared in $1735.93 \mathrm{~cm}^{-1}$ and $\mathrm{sp}^{3}$ alkyl $(\mathrm{C}$ $\mathrm{H})$ that appears in 2854.65 and $2927.94 \mathrm{~cm}^{-1}$. The symmetrical stretching vibration of the ester carbonyl group $(\mathrm{C}=\mathrm{O})$ which is common in both samples ${ }^{19}$. Symmetric and asymmetric bending vibration of $-\mathrm{CH}_{2}$ group are observed at $1371.39 \mathrm{~cm}^{-1}$ and $1454.33 \mathrm{~cm}^{-1}$, respectively for oil sample and the same bending vibrations of the $-\mathrm{CH}_{2}$ group of biodiesel was observed at $1369.46 \mathrm{~cm}^{-1}$ and $1448.54 \mathrm{~cm}^{-1}$ respectively ${ }^{20}$. The bands at 1026.13 and $1029.99 \mathrm{~cm}^{-1}$ correspond to $\mathrm{C}-\mathrm{O}$ stretching for oil sample and biodiesel, respectively. In addition, the peak at $1163.93 \mathrm{~cm}^{-1}$ in the triglyceride spectrum corresponds to the stretching vibration of the $\mathrm{C}-\mathrm{O}$ group attached to $-\mathrm{CH}_{2}$, which converts to the peak at $1176.58 \mathrm{~cm}^{-1}$ in the methyl ester group $\left(\mathrm{CO}-\mathrm{O}-\mathrm{CH}_{3}\right)$, attributed to the stretching vibration of C-O group attached to $-\mathrm{CH}_{3}{ }^{21}$. The reduction of $\mathrm{CH}_{2}$-Ogroups in oil and the appearance of $\mathrm{CH}_{3}-\mathrm{O}$ - vibrations in biodiesel were obvious ${ }^{22}$. After comparison of the two FTIR spectra, it can be concluded that the transesterification reaction had progressed successfully.

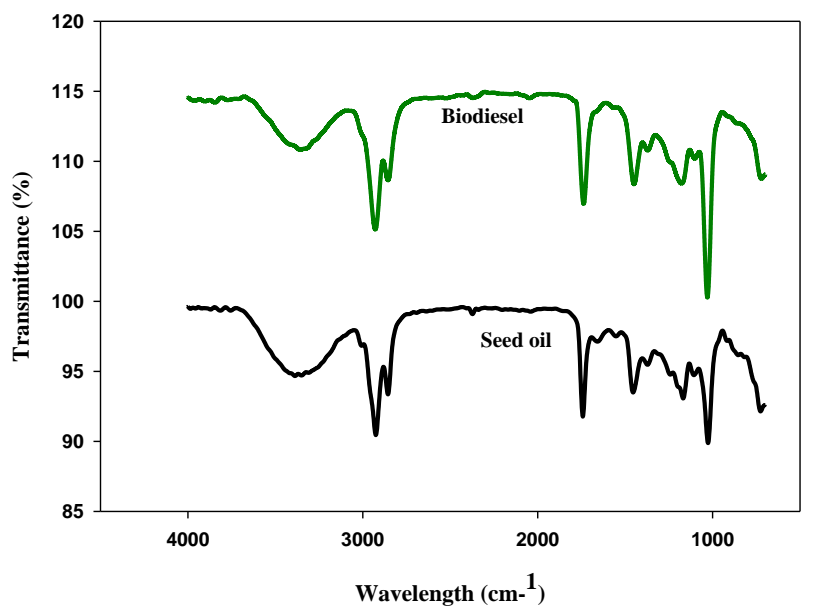

Fig. 10. FT-IR spectra of oil and produced biodiesel.

\section{Thermogravimetric Analysis}

Thermogravimetric analysis (TGA) is a simple and convenient way of monitoring transesterification reaction and the boiling point of esters. A simple TGA curve for the biodiesel sample is shown in Fig. 11. A weight loss of $5.46 \%$ occurred in the temperature region of 25 to $76{ }^{\circ} \mathrm{C}$ due to the dehydration of moisture present in the sample. In the temperature region of 76 to $153{ }^{\circ} \mathrm{C}$, a weight loss of $6.14 \%$ occurred due to the evaporation of trace amount of methanol that may have not been completely removed during the purification step. A significant weight loss of $74.38 \%$ occurred in the region of 153 to $236{ }^{\circ} \mathrm{C}$ due to the evaporation of biodiesel. A weight loss of $9.24 \%$ occurred in the temperature region of 236 to $347{ }^{\circ} \mathrm{C}$ due to the 
vaporization of trace amount of esters of unsaturated fatty acids remaining in the sample. The next weight loss occurred from 347 to $599{ }^{\circ} \mathrm{C}$ due to the thermal decomposition of mono-, di- and triglyceride residues. The weight then started to show a steady decrease in mass and from around $460{ }^{\circ} \mathrm{C}$, the weight of the sample became almost constant and at the maximum temperature of $600{ }^{\circ} \mathrm{C}$, $2.28 \%$ of the sample remained.

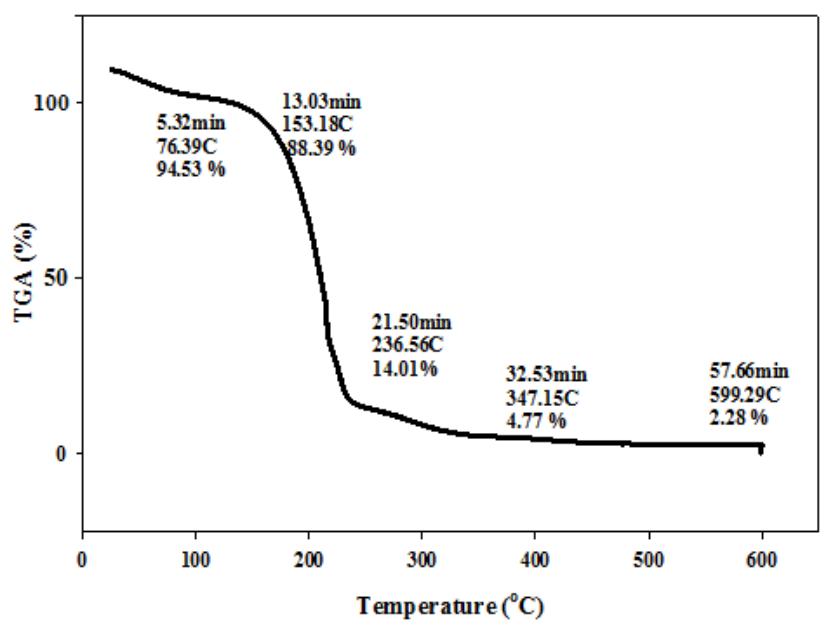

Fig. 11. TGA curve obtained for produced biodiesel.

\section{Physico-chemical characterization of produced biodiesel}

Various physico-chemical properties of the biodiesel were determined and compared with biodiesel standard. Table III lists some of the physico-chemical properties of the produced biodiesel. On modification of the extracted oil into biodiesel by two-step process, the fuel properties had shown significant improvement. The density and viscosity of the produced biodiesel lied within the standard range and therefore it would lead to proper atomization resulting in proper combustion followed by lower emissions and exhaust smoke. The biodiesel would also be able to provide sufficient lubrication for the precision fit of fuel injection pumps. The biodiesel will be safe to handle and store owing to its high flash point and would not have any problems during cold weather operations because its pour point lies within the standard range. The acid value and FFA content indicate that there is less chance of this fuel to form acidic solutions which would cause corrosion and deterioration of fuel properties.

Almost no moisture was detected in the produced biodiesel which means that there is no chance of moisture to block the flow of biofuel, promote microbial growth and lead to increased corrosion of fuel systems. The ash content was lower than the biodiesel standard and it indicates that there is lower risk of smoke emission from this biodiesel. The high carbon residue can lead to clogging of fuel filters and this may be attributed to the presence of trace amount of glycerol and soap in the produced fuel. The calorific value of the biodiesel was almost $93 \%$ of the standard and this lower calorific value is attributed to high oxygen content of the fuel which is also confirmed by elemental analysis. Since the cetane number of the fuel is high, its can easily combust in the internal combustion engines. Therefore this fuel can be implemented in internal combustion engines without any hardware modification.

Table 3. Physico-chemical characterization of produced biodiesel. ${ }^{23-25}$

\begin{tabular}{|c|c|c|c|c|}
\hline \multirow[t]{2}{*}{ Property Specification } & \multicolumn{2}{|c|}{$\begin{array}{c}\text { Biodiesel Standard } \\
\text { ASTM D6751 }\end{array}$} & \multirow{2}{*}{$\begin{array}{l}\text { Produced } \\
\text { Biodiesel }\end{array}$} & \multirow{2}{*}{$\begin{array}{c}\text { Commercial } \\
\text { Biodiesel }\end{array}$} \\
\hline & Test Method & Limits & & \\
\hline Density at $15^{\circ} \mathrm{C}, \mathrm{g} / \mathrm{cm}^{3}$ & ASTM D 1298 & 0.88 & 0.875 & 0.8445 \\
\hline Kinematic Viscosity $40{ }^{\circ} \mathrm{C}$, cSt & ASTM D 445 & $1.9-6.0$ & 4.278 & 2.71 \\
\hline Kinematic Viscosity $100^{\circ} \mathrm{C}, \mathrm{cSt}$ & ASTM D 445-65 & - & 2.152 & - \\
\hline Flash Point, ${ }^{\circ} \mathrm{C}$ & ASTM D 93 & $130 \mathrm{~min}$ & 152 & 65 \\
\hline Pour Point, ${ }^{\circ} \mathrm{C}$ & ASTM D 97 & -15 to -16 & -5 & -20 \\
\hline Acid value, $\mathrm{mg} \mathrm{KOH} / \mathrm{g}$ & ASTM D664 & $0.5 \max$ & 0.449 & 0.34 \\
\hline FFA, $\%$ & IP $1 / 58$ & $0.40 \max$ & 0.325 & \\
\hline Water content, vol\% & IP $74 / 57$ & 0.05 & - & Nil \\
\hline Ash content, \% (w/w) & ASTM D 482-63 & $0.02 \max$ & 0.0079 & 0.02 \\
\hline Carbon residue, $\%(\mathrm{w} / \mathrm{w})$ & ASTM-D $189-65$ & $0.05 \max$ & 0.0166 & 0.05 \\
\hline Calorific value, $\mathrm{MJ} / \mathrm{kg}$ & ASTM -D 240 & 38.586 & 39.0133 & 44.5 \\
\hline Sulfur content, $\%$ & ASTM -D 129-64 & 0.07 & 0.0 & 0.905 \\
\hline Cetane number & ASTM D613 & $47 \mathrm{~min}$ & 47 & 51 \\
\hline Sulfated ash content, $\%$ mass & ASTM D874 & $0.002 \max$ & 0.0007 & \\
\hline
\end{tabular}




\section{Conclusions}

The present study was successful in investigating a low cost, high FFA feedstock for biodiesel production. The twostep process utilized for the production of biodiesel in the current research was successful in improving the properties of the extracted oil in terms of FFA content, viscosity, pour point, flash point, making the produced biofuel quite suitable as an alternative diesel fuel. The biodiesel was found to contain permissible amounts of sulfur and almost $0 \%$ moisture content. Although most of the properties were on par with international standards, the biodiesel was found to contain high carbon residue and to possess high nitrogen content and its calorific value was found to be $7 \%$ lower than the standard value. The high carbon residue is an indication of the presence of glycerol in the purified biodiesel. The presence of traces of methanol and glyceride residues was also detected by thermogravimetric analysis so further investigation on the purification process of the produced biodiesel should be carried out. Further research and development should be carried on additional fuel property measures, long-term run and wear analysis of biodiesel fueled engine.

\section{Acknowledgment}

S.I. is grateful to the Ministry of Science and Technology, Government of the People's Republic of Bangladesh for providing the financial support to carry out the research work.

\section{References}

1. Atabani, A. E., I. A. Badruddin, T. M. I. Mahlia, H. H. Masjuki, M. Mofijur, K. T. Lee and W. T. Chong, 2013. Fuel Properties of Croton megalocarpus, Calophyllum inophyllum, and Cocos nucifera (coconut) Methyl Esters and their Performance in a Multicylinder Diesel Engine. Energy Technol. 1, $685-694$.

2. Palash, S. M., H. H. Masjuki, M. A. Kalam, A. E. Atabani, I. M. Rizwanul Fattah, and A. Sanjid, 2015. Biodiesel production, characterization, diesel engine performance, and emission characteristics of methyl esters from Aphanamixis polystachya oil of Bangladesh. Energy Convers. Manag. 91, 149-157.

3. Kumar, R., K. T. Prasanna, and B. Gowda, 2014. Evaluation of Aphanamixis polystachya (Wall.) R. Parker as a potential source of biodiesel. J. Biochem. Technol. 3(5),128-133.

4. BaümLer, E. R., M. E. Carrín, and A. A. Carelli, 2016. Extraction of sunflower oil using ethanol as solvent. J. Food Eng.178, 190-197.

5. Bhutada, P. R., A. J. Jadhav, D. V. Pinjari, P. R. Nemade, and R. D. Jain, 2016. Solvent assisted extraction of oil from Moringa oleifera Lam. seeds. Ind. Crops Prod. 82, 74-80.

6. Widayat, A. D. K. Wibowo, and Hadiyanto, 2013. Study on production process of biodiesel from rubber seed (hevea brasiliensis) by in situ (trans)esterification method with acid catalyst. Energy Procedia. 32, 64-73.

7. Pramanik, K. 2003. Properties and use of jatropha curcas oil and diesel fuel blends in compression ignition engine. Renew. Energy 28(2), 239-248.

8. Conceição, M. M., R. A. Candeia, F. C. Silva, A. F. Bezerra, V. J. Fernandes, and A. G. Souza, 2007. Thermoanalytical characterization of castor oil biodiesel. Renew. Sustain. Energy Rev.11(5), 964-975.

9. Ramadhas, A., S. Jayaraj, and C. Muraleedharan, 2005. Biodiesel production from high FFA rubber seed oil. Fuel 84(4), 335-340.

10. Dorado, M. P., E. Ballesteros, J. A. De Almeida, C. Schellert, H. P. Löhrlein, and R. Krause, 2002. An alkalai-catalyzed transesterification process for high free fatty acid waste oils. Trans. Am. Soc. Agric. Eng. 45(3), 525-529.

11. Naik, M., L. Meher, S. Naik, and L. Das, 2008. Production of biodiesel from high free fatty acid Karanja (Pongamia pinnata) oil. Biomass and Bioenergy 32(4),354-357.

12. Canakci, M. and J. Van Gerpen, 2001. Biodiesel production from oils and fats with high free fatty acids. Trans. ASAE 44(6), 1429.

13. Fillières, R., B. Benjelloun-MLayah, and M. Delmas, 1995. Ethanolysis of rapeseed oil: Quantitation of ethyl esters, mono-, di-, and triglycerides and glycerol by highperformance size-exclusion chromatography. J. Am. Oil Chem. Soc. 72(4), 427-432.

14. Dorado, M. P., E. Ballesteros, F. J. López, and M. Mittelbach, 2004. Optimization of Alkali-Catalyzed Transesterification of Brassica Carinata Oil for Biodiesel Production. Energy \& Fuels 18(1), 77-83.

15. Veljkovic, V., S. Lakicevic, O. Stamenkovic, Z. Todorovic, and M. Lazic, 2006. Biodiesel production from tobacco (Nicotiana tabacum L.) seed oil with a high content of free fatty acids. Fuel, 85(17-18), 2671-2675.

16. Demirbaş, A. and H. Kara, 2006. New Options for Conversion of Vegetable Oils to Alternative Fuels. Energy Sources, Part A Recover. Util. Environ. Eff., 28(7), 619-626.

17. Lapuerta, M., O. Armas, and J. Rodriguez-Fernandez, 2008. Effect of biodiesel fuels on diesel engine emissions. Prog. energy Combust. Sci. 34(2), 198-223.

18. Rao, P. V, 2011. Effect of properties of Karanja methyl ester on combustion and NOx emissions of a diesel engine. J. Pet. Technol. Altern. Fuels 2(5), 63-75.

19. O'Donnell, S., I. Demshemino, M. Yahaya, I. Nwandike, and L. Okoro, 2013. A review on the spectroscopic analyses of biodiesel. Eur. Int. J. Sci. Technol. 2(7), 137-146.

20. Safar, M., D. Bertrand, P. Robert, M. F. Devaux, and C. Genot, 1994. Characterization of edible oils, butters and margarines by Fourier transform infrared spectroscopy with attenuated total reflectance. J. Am. Oil Chem. Soc. 71(4), 371-377.

21. Rafati, A., Tahvildari, K. and Nozari, M., 2019. Production of biodiesel by electrolysis method from waste cooking oil using heterogeneous $\mathrm{MgO}-\mathrm{NaOH}$ nano catalyst. Energy Sources, Part A Recover. Util. Environ. Eff. 41(9), 1062-1074.

22. Elkady, M. F., Zaatout, A. and Balbaa, O., 2015 Production of Biodiesel from Waste Vegetable Oil via KM Micromixer. J. Chem. 2015, 1-9.

23. Barabas, I. and I.-A. Todoru, 2011. Biodiesel Quality, Standards and Properties. Biodiesel- Quality,Emissions and By-Products, InTech.

24. Kaur, H., G. Singh, S. Yusup, B. Abdullah, and K. Wai, 2017. Refi ning of crude rubber seed oil as a feedstock for biofuel production. J. Environ. Manage. 203, 1011-1016.

25. Singh, D., D. Sharma, S. L. Soni, S. Sharma, and D. Kumari, 2019. Chemical compositions, properties, and standards for different generation biodiesels: A review. Fuel 253, 60-71. 